\title{
Target Neuron Controls the Integrity of Afferent Axon Phenotype: A Study on the Purkinje Cell-Climbing Fiber System in Cerebellar Mutant Mice
}

\author{
Ferdinando Rossi, Aleksandar Jankovski, and Constantino Sotelo \\ Neuromorphologie, Développement, Evolution, INSERM U. 106, Hôpital de la Salpétrière, 75651 Paris Cedex 13, \\ France
}

The effects of target loss on adult axonal arbors were investigated by comparing the morphological changes of adult climbing fibers in several mutant mouse strains where Purkinje cells slowly degenerate (namely, Lurcher, nervous, Purkinje cell degeneration, and tambaleante), with those occurring after a fast Purkinje cell death induced by mechanical lesions of the adult mouse cerebellum.

In each of the different mutations, Purkinje cells displayed distinctive structural modifications. However, a set of regressive changes common to all strains could be disclosed, mostly dendritic atrophy and a progressive axonal retraction with the hypertrophy of recurrent collaterals. Climbing fibers that contacted such degenerating neurons also showed abnormal morphological features, consisting in the presence of extensive perisomatic plexuses, whereas peridendritic branches were atrophic or absent. In Lurcher mice, target-deprived climbing fibers were strictly confined around the granular-molecular layer interface and never penetrated into the molecular layer. Similar terminal plexuses at the level of the former Purkinje cell layer were observed in the other mutants. However, in the latter cases, atrophic terminal arbors were also present in the molecular layer, being confined to the deep portions in nervous, while spanning its whole extent in Purkinje cell degeneration and tambaleante mice.

Following mechanical lesions, atrophic target-deprived climbing fibers were exclusively located in the molecular layer. In addition, some of the Purkinje cells that survived after the injury displayed regressive modifications similar to those observed in mutant mice, and their climbing fibers were characterized by perisomatic plexuses.

These results show that the normal relationship between the climbing fiber and its Purkinje cell is already disrupted during the slow degeneration of the target neuron. As a consequence, the phenotypic pattern of target-deprived climbing fibers reflects the preceding interactions with

\footnotetext{
Received June 28, 1994; revised Sept. 6, 1994; accepted Sept. 14, 1994.

We thank Dr. D. E. M. Lawson for the gift of anti-calbindin antibody and Dr J.-L. Guénet for his continuous help providing the mutants, and particularly for allowing the use of tambaleante mice. We also thank Denis I ecren for his photographic work and Marie-Pierre Morel for breeding the mutant mice. F.R. was supported by a postdoctoral fellowship from the Fondation Simone et Cino Del Duca, Paris; A.J. was supported by an undergraduate fellowship from the Fondation pour la Recherche Médicale, Paris.

Correspondence should be addressed to Dr. Constantino Sotelo, Neuromorphologie, Développement, Evolution, INSERM U. 106, Hôpital de la Salpétrière, 47 Boulevard de l'Hôpital, 75651 Paris Cedex 13, France.

Copyright $\odot 1995$ Society for Neuroscience $0270-6474 / 95 / 152040-17 \$ 05.00 / 0$
}

their postsynaptic neurons and it is determined by the onset time and progression rate of Purkinje cell degeneration.

[Key words: Purkinje cell, climbing fiber, axon-target interaction, plasticity, atrophy, Lurcher, nervous, Purkinje cell degeneration, tambaleante, mutant mouse, cerebellum, inferior olive]

During development, neuronal survival and acquisition of phenotype are regulated through retrograde influences exerted by postsynaptic cells (Purves et al., 1988; Oppenheim, 1991). By contrast, in the adult, target-derived support does not seem to be always needed for neuronal survival, but it still controls several structural and functional features of afferent nerve cells (Sofroniew et al., 1990, 1993). Among these features, of particular interest is the dynamic control on the maintenance and plasticity of axon arbors in both physiological and pathological conditions. For instance, axon-target interactions have been proposed to underlay structural modifications associated with learning processes (Glanzman et al., 1990; Schacher and Montarolo, 1991) as well as those observed in the case of postlesion remodeling (see Steward, 1991, 1992).

One of the most direct approaches to investigate target influences on the morphology of adult axonal arbors is to examine the structural modifications that occur following target deprivation. The question whether an adult axon is able to persist in its projection area after the disappearance of its postsynaptic neurons has been addressed in several systems of the adult mammalian brain (Peterson and Moore, 1980; Curtis and Malik, 1985; Isacson et al., 1985; Walker and McAllister, 1986; Peschanski and Besson, 1987; Nothias et al., 1988; Woodward et al., 1989; Pearson et al., 1992; de la Cruz et al., 1994). Although the conclusions of these studies have been somewhat controversial, most of the reports generally indicate that targetdeprived axons become atrophic but remain within their projection areas for fairly long times.

This issue has been recently investigated in the olivocerebellar pathway. Because of its peculiar anatomical organization (Ramón y Cajal, 1911; Ito, 1984), this system offers the unique chance to study the fine morphology of single identified inferior olivary axon arbors, the climbing fibers, following different experimental manipulations of their main target neurons in the cerebellar cortex, the Purkinje cells. Experiments where a fast Purkinje cell degeneration was induced by means of intraparenchymal application of kainic acid (Armengol et al., 1989; Rossi et al., 1993) or propidium iodide (Rossi et al., 1993) have shown that adult target-deprived climbing fibers lose their 
peripheral branches but remain for several months in the molecular layer of the cerebellar cortex. In addition, other regressive morphological alterations, referred to as altered axon-target interactions, affect climbing fibers whose Purkinje cells were exposed, but survived after a kainic acid injection in the adult rat cerebellar cortex (Rossi et al., 1994b).

An alternative model to address this question in the olivocerebellar system is represented by mutant mouse strains where Purkinje cells are the primary cell target. In principle, this approach allows the overcoming of one of the most important drawbacks of neurotoxin-induced lesions, that is, the possible direct action of the toxin on afferent axons. Another major difference between lesion experiments and the study of mutant mice concerns the progression rate of Purkinje cell death, which is almost instantaneous in the former and much slower in the latter. Indeed, the slowly progressing degenerative processes of mutant Purkinje cells might affect the structural features of afferent axons even prior the actual target death, such as observed in mutations that are not lethal for Purkinje cells (Guénet et al., 1983; Sotelo, 1990a,b) or when these neurons survive after kainic acid application (Rossi et al., 1994b). Finally, the different times and modes of onset and progression of Purkinje cell degeneration in the different mutant strains makes it possible to compare the behavior of climbing fibers that have lost their targets at different life stages.

In order to address these issues, we have analyzed four different mutant mice strains: (1) Lurcher ( $L c$; Caddy and Biscoe, 1979; Dumesnil-Bousez and Sotelo, 1992), where Purkinje cells start to die during the second postnatal week; (2) nervous ( $n r$; Sidman and Green, 1970; Landis, 1973; Sotelo and Triller, 1979; Wassef et al., 1987), where the onset of Purkinje cell death is delayed and selectively affects a subset of these neurons; (3) Purkinje cell degeneration (pcd; Mullen et al., 1976; Landis and Mullen, 1978), where virtually all Purkinje cells die after the third postnatal week; (4) tambaleante ( $t b l$; Wassef et al., 1987), where the degeneration of Purkinje cells starts at about 2 months of age and slowly progresses for several weeks up to the almost complete disappearance of these neurons. Our analysis was focussed on adult individuals from these strains, where we examined the structural features of surviving Purkinje cells as well as those of climbing fibers, which still contacted or had lost their targets. In addition, in order to compare climbing fiber modifications that follow target loss in mutant animals with those occurring in the case of a fast lesion-induced Purkinje cell death, we have examined the morphology of target-deprived climbing fibers following mechanical lesions of the cerebellar cortex in normal adult mice. Our aim was that of relating the present observations to the results obtained from other mutations (Guénet et al., 1983; Sotelo, 1990a,b) or toxin-lesioned cerebella (Armengol et al., 1989; Rossi et al., 1993, 1994b) in order to disclose some common phenomena and/or mechanisms that could help us to elucidate the role played by target neurons in the maintenance and plasticity of their afferent axonal arbors.

\section{Materials and Methods}

Animals. Mutant mice were obtained from Dr. J.-L. Guénet (Institut Pasteur, Paris). The animals considered in the study were $10 \mathrm{Lc}$ mice (C57B1 $\times$ CBA background), aged 55 to $75 \mathrm{~d} ; 4 n r$ mice $(\mathrm{C} 3 \mathrm{HeB} / \mathrm{J}-\mathrm{Pas}$ background), aged 53 to $128 \mathrm{~d} ; 3$ pcd mice (C57CBA background), aged 65 to $104 \mathrm{~d} ; 6 \mathrm{tbl}$ (DW/J-Pas background), aged 50 to $615 \mathrm{~d}$. Control animals $(n=4)$ as well as those considered for mechanical lesion experiments $(n=4)$ were OF1 adult mice (body weight 30 to $35 \mathrm{~g}$ ) obtained from IFFA CREDO (Lyon, France).

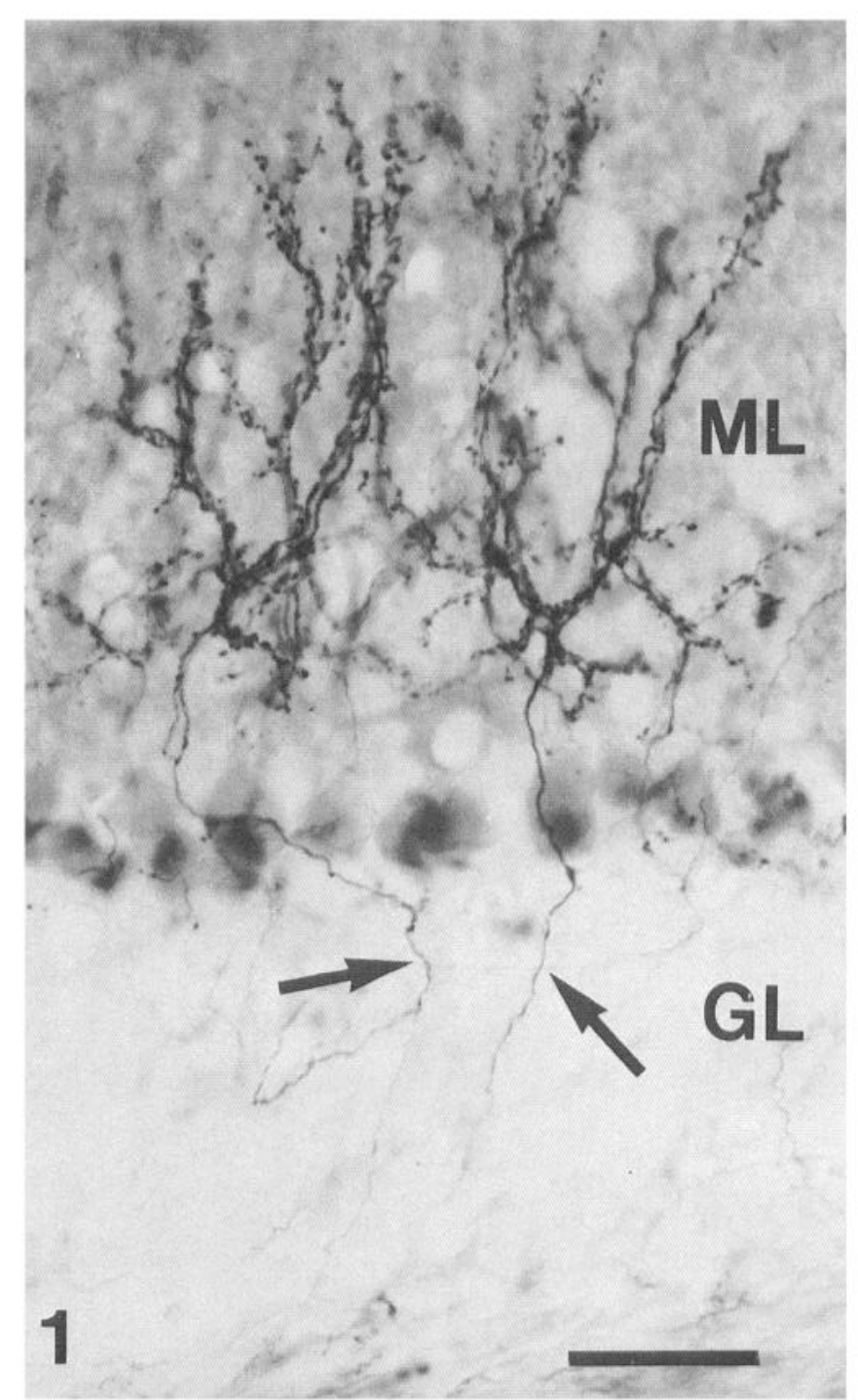

Figure 1. Purkinje cells and climbing fibers in the normal adult mouse. The micrograph shows two olivary axons (arrows) that penetrate into the molecular layer where they break in extensive terminal arbors impinging upon the proximal compartment of the Purkinje cell dendritic tree. $M L$, molecular layer; $G L$, granular layer. Scale bar, 40 $\mu \mathrm{m}$.

Cerebellar lesions. The technique applied to obtain mechanical lesions of the cerebellar cortex was basically the same described by Dusart and Sotelo (1994). Briefly, the adult OF1 mice were deeply anesthetized by means of chloral hydrate $(400 \mathrm{mg} / \mathrm{kg})$ and placed in a stereotaxic frame. The occipital bone was exposed and a small hole was drilled in its posterior aspect around the midline. A knife made by a small piece of razor blade $(0.5 \mathrm{~mm}$ wide and $3-3.5 \mathrm{~mm}$ long) was introduced into the cerebellum from the right side of the vermis and then turned towards the left. Thereafter, the skin was sutured, the animal returned to its cage, and was given free access to food and water. Survival times after the lesion ranged 15 to $35 \mathrm{~d}$. Seven to $10 \mathrm{~d}$ before the end of this period the animals were again anesthetized to receive tracer injections in the inferior olive (see below).

Tracer injections and histological procedures. In order to visualize the olivocerebellar system, the axonal tracer Biotinylated Dextran Amine (BDA; 10,000 MW, Molecular Probes, Eugene, OR) was iontophoretically injected in the inferior olive. The animals were deeply anesthetized with chloral hydrate $(400 \mathrm{mg} / \mathrm{kg})$ and placed on a stereotaxic frame. The skin was incised over the head and neck regions and the muscles were retracted laterally. The atlanto-occipital membrane was cut and partially removed in order to expose the dorsal aspect of 

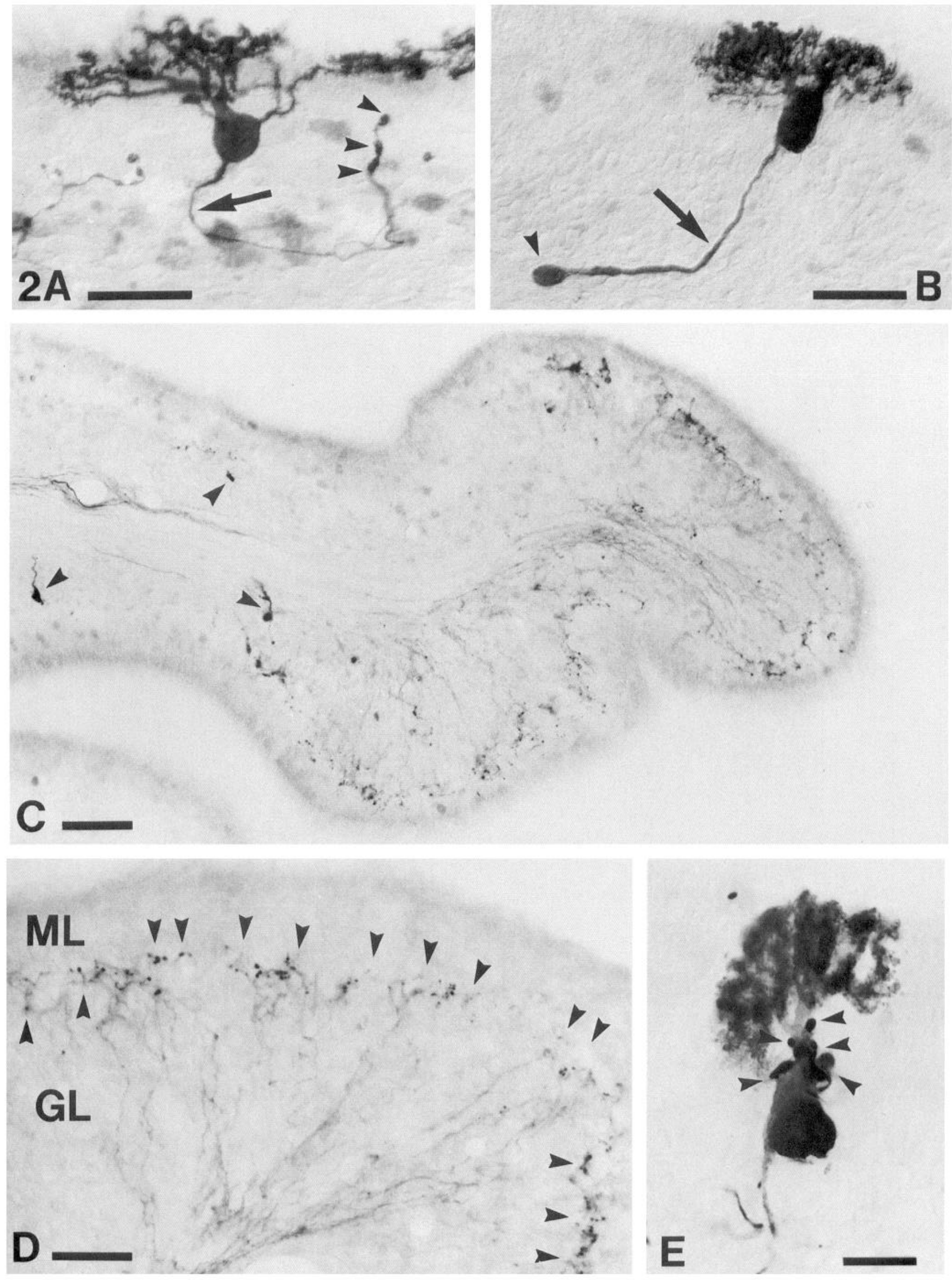

GL

D

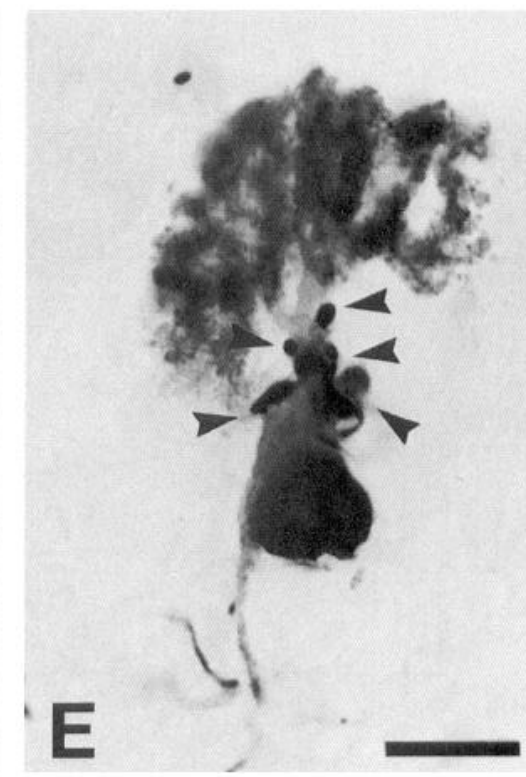


the medulla oblongata and the posterior cerebellar vermis. To inject the tracer into the inferior olive, pipettes were placed at the posterior edge of the fourth ventricle on the left side of brainstem close to the midline and lowered 2 to $2.1 \mathrm{~mm}$ from the surface with an inclination of $30^{\circ}$ to $35^{\circ}$. The glass pipettes (inner tip diameter 25 to $35 \mu \mathrm{m}$ ) were filled with $2-3 \mu$ l of a $10 \%$ solution of BDA in $0.12 \mathrm{M}$ phosphate buffer ( $\mathrm{pH}$ 7.2). Each animal received four to six injections made of positive current pulses of $7 \mu \mathrm{A}, 5 \mathrm{sec}$ on and $5 \mathrm{sec}$ off, delivered by a Midgard CS3 iontophoretic device. Each injection lasted $15 \mathrm{~min}$ and the same pipette was used twice. Thereafter, the muscles and the skin were sutured, the mice returned to their cages, and were let survive for another 7 to $10 \mathrm{~d}$.

After the end of this period, under renewed general anesthesia (chloral hydrate $400 \mathrm{mg} / \mathrm{kg}$ ) the mice were transcardially perfused with 300 $500 \mathrm{ml}$ of $4 \%$ paraformaldehyde in $0.12 \mathrm{M}$ phosphate buffer ( $\mathrm{pH} 7.2$ ). The dissected brains were kept in the same fixative overnight at $4^{\circ} \mathrm{C}$ and then transferred to $30 \%$ sucrose in the same buffer at $4{ }^{\circ} \mathrm{C}$ until they sunk. The cerebellum and the brainstem were isolated and cut by means of a freezing microtome in $30 \mu \mathrm{m}$ thick sagittal or frontal sections, respectively. The sections were collected in phosphate-buffered saline (PBS) and incubated for $30 \mathrm{~min}$ in $0.3 \% \mathrm{H}_{2} \mathrm{O}_{2}$ in PBS to quench endogenous peroxidase and then for $2 \mathrm{hr}$ in the avidin-biotin-peroxidase complex (ABC; Vector, Burlingame, CA), diluted 1:100 in PBS with $0.25 \%$ Triton $\mathrm{X}-100$. The tracer was finally visualized by means of the diaminobenzidine (DAB) reaction with $0.04 \%$ nickel ammonium sulfate to obtain a black reaction product. In order to stain Purkinje cells on the same sections, these were incubated overnight at room temperature with an anti-calbindin antibody (gift of Dr. D. E. M. Lawson, Spencer et al., 1976), diluted 1:40000 in PBS with $0.2 \%$ gelatine and $0.25 \%$ Triton-X 100 . The ensuing immunohistochemical staining was performed according to the $\mathrm{ABC}$ method. $\mathrm{DAB}$ reaction was performed without nickel ammonium sulfate in order to obtain a brown labeling. The reacted sections were mounted on chrome alum gelatinized slides, air dried, dehydrated, and coverslipped. The histological preparations were examined by bright-field or Nomarski interference contrast using a Zeiss Axiophot light microscope.

\section{Results}

Climbing fibers and Purkinje cells in the normal adult mouse Our observations on Purkinje cells and climbing fibers in normal adult mice largely fit with previous descriptions of this species (Ramón y Cajal, 1911). Purkinje cells were distributed in the typical monolayer with extensive monoplanar dendritic trees. Their rather thin and smooth axons run straight across the granular layer and the white matter directed to the cerebellar nuclei. Fine recurrent collaterals could be barely disclosed in the granular layer ending in a few terminal processes just below the line of Purkinje cell somata.

Labeled olivary axons (Fig. 1), characterized by their fine caliber and beaded appearance, run from the white matter across the granular layer along winding trajectories. Such axons elon gated into the molecular layer to break into their terminal arbors fairly above the Purkinje cell somata close to the branching point of the primary dendrite. The climbing fibers were typically constituted by a few thick smooth ramifications and numerous fine varicose branches twining around the proximal Purkinje cell dendrites.

\section{Lurcher}

Purkinje cells. The majority of the rare surviving Purkinje cells in the adult $L c$ cerebellum were located in lobule $\mathrm{X}$ or in the adjacent ventral aspect of lobule IX (Fig. $2 A$ ). In line with previous descriptions of younger $L c$ mice (Caddy and Biscoe, 1979; Heckroth et al., 1990; Dusmenil-Bousez and Sotelo, 1992,) these cells displayed atrophic and randomly oriented dendritic trees, made of several primary ramifications that ended in small terminal networks of spiny branchlets. Mildly thickened axons bearing several swellings of moderate size emerged either from the soma or a primary dendrite. In some instances, they could be followed up to the folial white matter, but often they abruptly ended in the granular layer with one or a few varicosities. In addition, some of such axons took the recurrent course of arciform fibers (Ramón y Cajal, 1928), which ended in the upper granular layer or into the molecular layer with poorly developed terminal plexuses, bearing very few enlarged boutons reminiscent of retraction clubs (Ramón y Cajal, 1928).

Another smaller subset of surviving Purkinje cells (Fig. 2B) was scattered along the other cortical lobules. These cells were characterized by oversized somata and conspicuously thickened axons, which often displayed one or a few large torpedoes. Recurrent collaterals or arciform fibers were never present, and these axons ended with large retraction clubs in the mid granular layer or in the white matter.

Climbing fibers. Labcled olivoccrebcllar fibers could be recognized along their course from the restiform body through the cerebellar white matter, although they appeared thinner and less intensely stained than their counterparts in normal animals. A rather prominent terminal field was present within the deep nuclei. Then, the olivary axons run in thick bundles along the folial white matter towards the cerebellar cortex where they terminated in discrete bands. In the granular layer, these axons took tortuous courses, resulting in a loose network of neuritic processes (Fig. $2 C, D$ ). Branching within this layer was sometimes evident but the evaluation of its frequency and extent was hindered by the intermingling of several different profiles.

The partial coverage of the inferior olive obtained by our injections together with the small number of surviving Purkinje cells allowed us to label only very few climbing fibers that still retained their target neuron (Fig. $2 E$ ). Such arbors were made of a few short varicose branches distributed around the apical pole of the soma and/or extended for short distances along the most proximal dendritic ramifications.

By contrast, numerous target-deprived climbing fibers could be labeled along the whole extent of the cerebellar cortex (Fig. $2 C, D$ ). In line with previous descriptions (Wilson, 1976; Heckroth and Eisenman, 1988), the terminal field of these axons was strictly confined within a thin rim of cortex at the level of the former Purkinje cell layer, where the branches from different

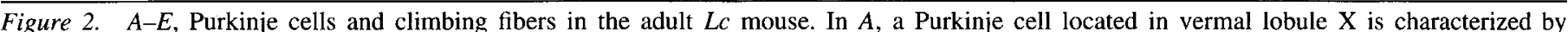

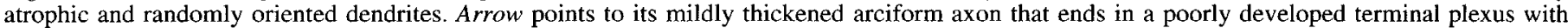

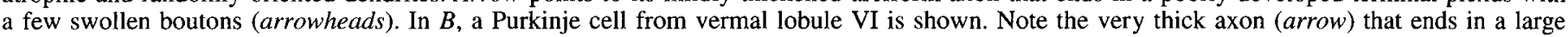

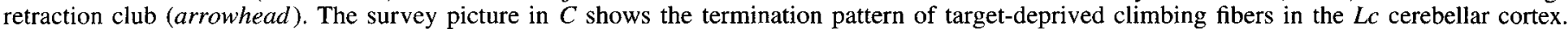

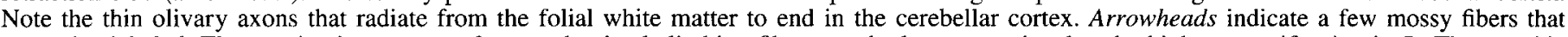

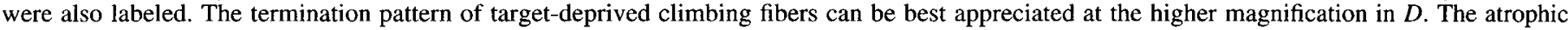

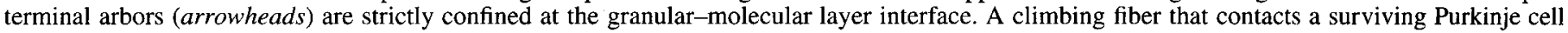

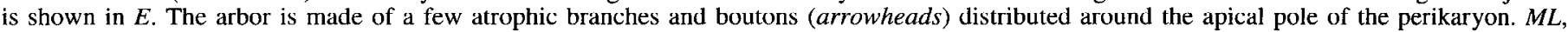
molecular layer; $G L$, granular layer. Scale bars: $30 \mu \mathrm{m}$ in $A, B$, and $D ; 50 \mu \mathrm{m}$ in $C ; 20 \mu \mathrm{m}$ in $E$. 
fihers largely intermingled to form a fine meshwork. Only occasionally, single profiles elongated further into the molecular layer. These terminal arbors were extremely atrophic, made of a few short branchlets with no preferential orientation in space, which bore sparse varicosities and rare enlarged boutons.

\section{Nervous}

Purkinje cells. In line with previous reports (Wassef et al., 1987), the surviving Purkinje cells in adult $n r$ mice were distributed in discrete parasagittal bands. In addition, a few Purkinje cells, that were either isolated or grouped in small clusters, were also present in the interstripe zones. Purkinje cells within the bands showed no overt abnormality in their dendritic trees and perikarya. By contrast, their axons sometimes appeared moderately thickened and often bore torpedoes (see Fig. $3 C$ ). Recurrent terminal plexuses were also mildly hypertrophic and, occasionally, contained enlarged boutons. Surviving Purkinje cells located outside such bands were usually affected by more severe structural modifications (Fig. 3A,B). Their dendritic trees were characterized by slight abnormalities in the branching pattern, a mild thickening of proximal ramifications, the presence of swellings at branching points, and unusually large amounts of spines on the main dendrites (see also Sotelo and Triller, 1979, concerning Purkinje cells in the cerebellar hemispheres). The axons were conspicuously thickened and often showed hypertrophic recurrent collaterals and arciform fibers, whereas corticofugal branches, when present, were usually thinner (Fig. $3 A$ ). One or several large torpedoes were a common feature along the course of such processes. Recurrent fibers ended in variably extended terminal plexuses, characterized by some round enlarged boutons, for the most developed at the granular-molecular layer interface or elongating into the molecular layer. Occasionally, thickened arciform axons abruptly ended in an oversized retraction club (Fig. $3 B$ ).

Climbing fibers. Among the climbing fibers that ended on surviving $n r$ Purkinje cells, two morphologically different types could be distinguished. The arbors impinging upon the Purkinje cells located within the bands displayed almost normal structural features (Fig. 3C). Only occasionally, there was a slight increase in the number of terminal branches around the perikaryon and the initial portion of the primary dendrite. By contrast, climbing fibers ending on Purkinje cells that survived within the interstripe areas (Fig. 3D,E) were characterized by rather thick perisomatic plexuses of varicose branches that also extended along the primary dendrite, whereas only a few thin atrophic branches, bearing sparse boutons, still contacted more distal dendritic ramifications. In a few instances, climbing fiber branches were completely absent around Purkinje dendrites, and the whole arbor was reduced to a few perisomatic varicosities.
Target-deprived climbing fibers (Fig. $3 F, G$ ) were frequently traced in the cortical areas where Purkinje cells had degenerated. Thin, dimly labeled axons, crossed the granular layer and terminated in two discrete locations. A rather thick terminal meshwork formed by the intermingling of numerous fine branches from different axons, somewhat similar to that observed in $L c$ mice, was present at the granular-molecular layer interface. In addition, atrophic arborizations radiated in the molecular layer, being usually confined within its deeper two-thirds. The latter arbors usually displayed the typical orientation perpendicular to the main axis of the folium. In both locations, the terminal arbors were mostly made of thin branches, with rare varicosities and occasional round enlarged boutons (Fig. 3G).

\section{Purkinje cell degeneration}

Purkinje cells. At the examined ages the effects of the $p c d$ mutation were fully developed and only rare Purkinje cells were present, for the most in vermal lobules IX and X (Fig. 4A,B). These cells showed atrophic dendritic trees, characterized by a severe loss of distal branches. Proximal ramifications were less affected, but they were usually studded with large amounts of spines. The axons of these cells were not thicker than normal, nor they did displayed torpedoes. Nevertheless, they were often characterized by long arciform recurrent collaterals that terminated in extensive terminal plexuses in the neighboring granular and molecular layers.

Climbing fibers. In our material, none of the few surviving Purkinje cells was contacted by a labeled olivary axon. By contrast, target-deprived arbors (Fig. 4C,D) were present along the whole cerebellar cortex, distributed in discrete stripes. Also, in $p c d$ mice, a fine meshwork of terminal ramifications was present at the level of the former Purkinje cell layer. In addition, monoplanar atrophic arbors, made of thin branches with sparse varicosities and a few round-shaped boutons, spanned the molecular layer. However, contrary to $n r$ climbing fibers, in the $p c d$ cerebellum the terminal network at the level of the Purkinje cell layer was less developed, whereas the arbors usually radiated up to the most superficial portion of the molecular layer (compare Figs. $3 G, 4 D$ ).

\section{Tambaleante}

Purkinje cells. Contrary to the other mutant strains, in which almost all Purkinje cells die during postnatal development or early adulthood, in most of the examined adult $t b l$ mice the mutation effects were still evolving. As a consequence, the amount of surviving Purkinje cells varied according to the age of the animals, and neurons at different stages of their degeneration could be disclosed in all the examined cases. Since the regressive modifications of $t b l$ Purkinje cells have not been re-

\footnotetext{
Figure 3. $A-G$, Purkinje cells and climbing fibers in the adult $n r$ mouse. Purkinje cells that survived in the interstripe zones are shown in $A$ and $B$. The Purkinje cell in $A$ displays a mildly thickened arciform axon (large arrow) that ends in a small terminal plexus (arrowheads) at the granularmolecular layer interface. The small arrow points to the thinner corticofugal axonal branch. The Purkinje cell in $B$ is characterized by swollen proximal dendrites and a prominent arciform axon, bearing two torpedoes (arrowheads) that terminates in an oversized retraction club (arrow). The climbing fiber shown in $C$ contacts a Purkinje cell located at the edge of a band of surviving Purkinje cells. Note the almost normal peridendritic distribution of the arbor, with only a few varicose branches that descend on the soma (arrowheads). Arrow indicates a torpedo along the Purkinje cell axon. Two examples of climbing fibers ending on Purkinje cells located outside the bands are presented in $D$ and $E$. Their terminal branches (arrowheads) envelope the somata and primary dendrites, whereas almost no ramifications are present around more distal dendrites. The picture in $F$ displays the distribution of target-deprived climbing fibers (arrowheads) in the $n r$ cerebellar cortex. The terminal network at the granularmolecular layer interface (arrowheads) and the atrophic branches that penetrate in the deep portion of the molecular layer (arrows) can be better appreciated in the higher magnification micrograph in $G$. $M L$, molecular layer; $G L$, granular layer. Scale bars: $40 \mu \mathrm{m}$ in $A-C$; $20 \mu \mathrm{m}$ in $D$ and $E$; $50 \mu \mathrm{m}$ in $F ; 30 \mu \mathrm{m}$ in $G$.
} 

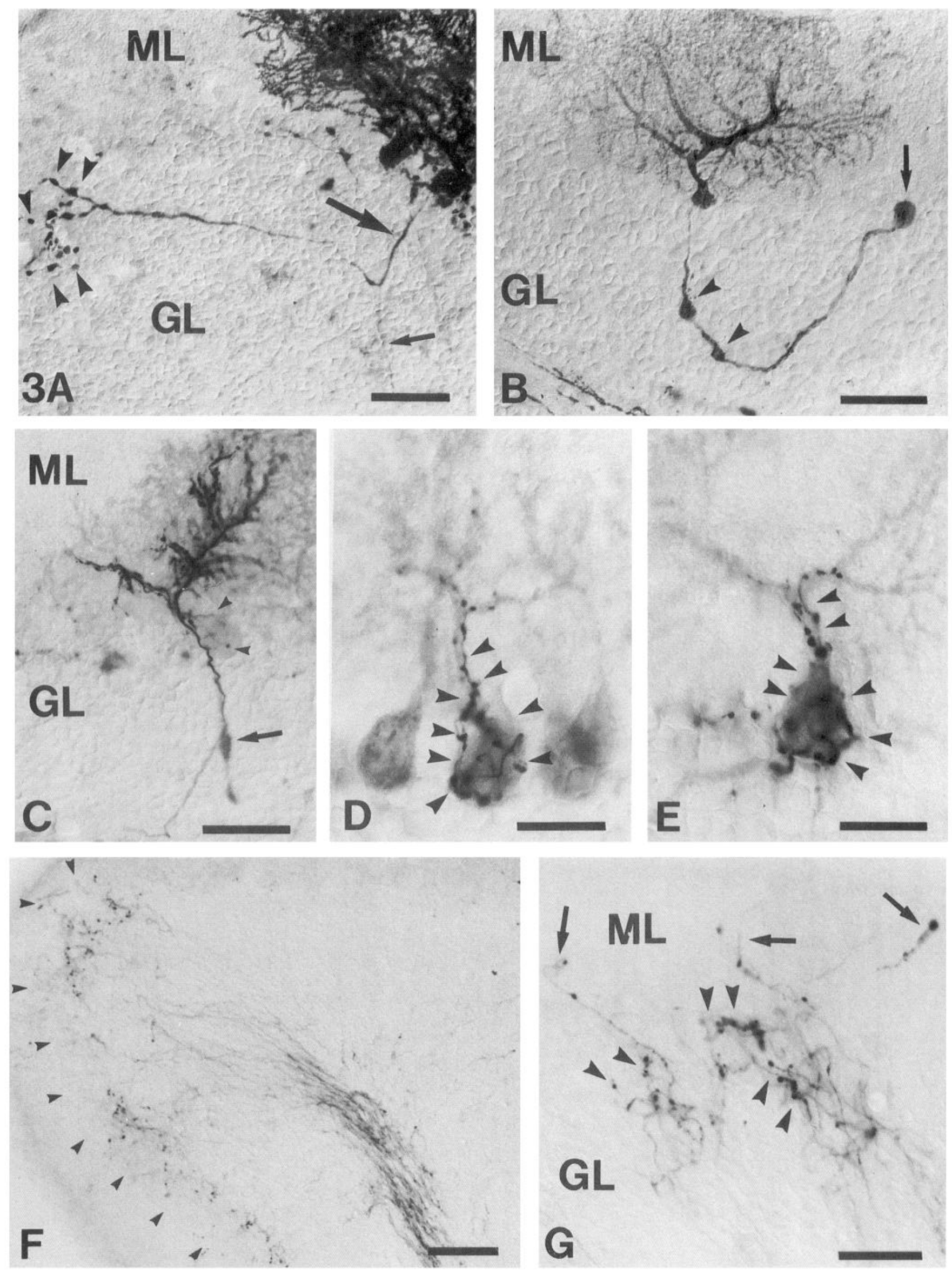

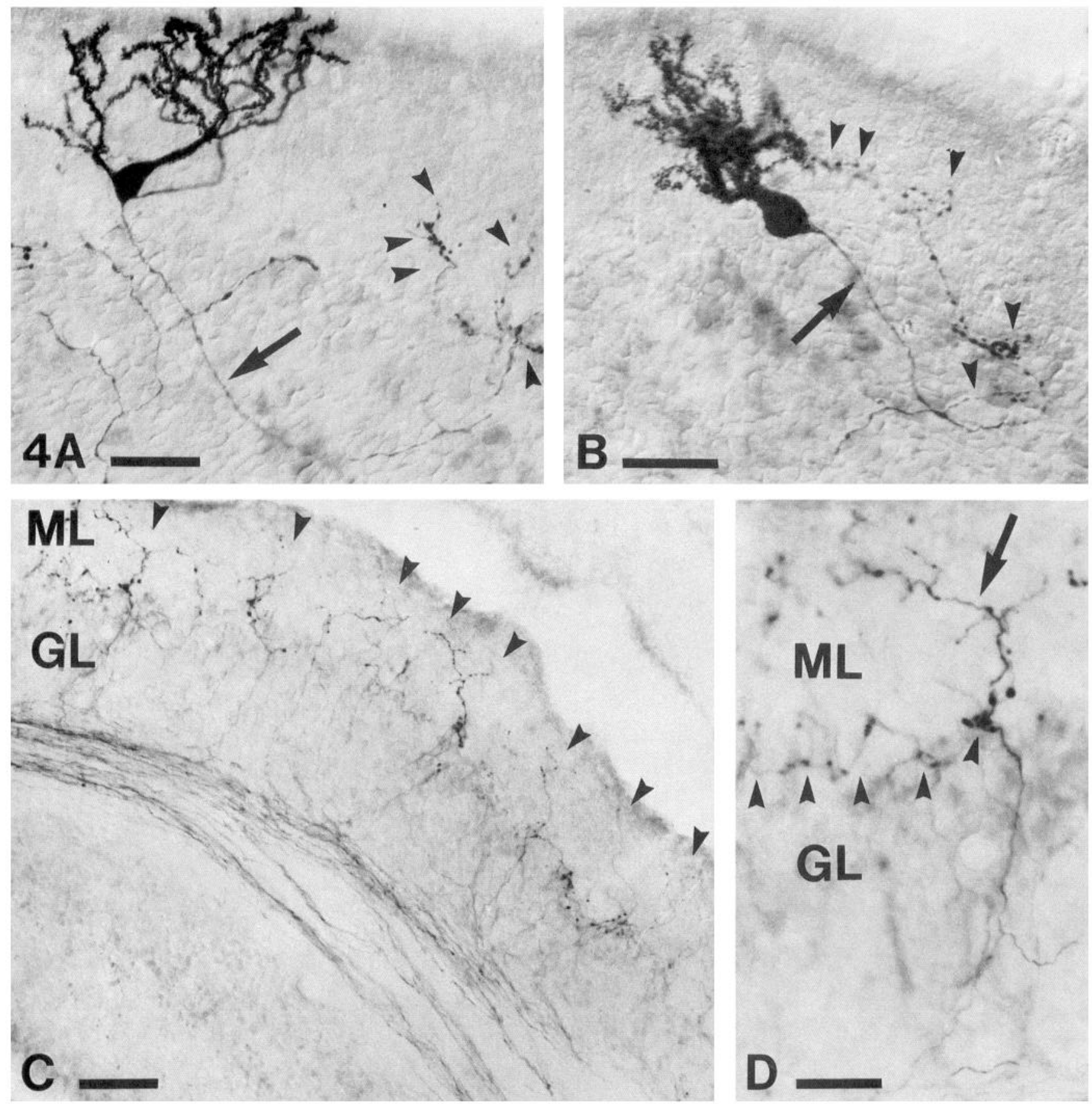

Figure 4. $A-D$, Purkinje cells and climbing fibers in the adult $p c d$ mouse. Two examples of Purkinje cells that survived in adult pcd mice are shown in $A$ and $B$. Note the atrophic dendritic trees, studded with numerous spines, and the fine arciform axons (arrows) ending with several terminal branches (arrowheads) that also extend into the lower region of the molecular layer. The survey picture in $C$ shows the terminal pattern of target-deprived climbing fibers (pointed by arrowheads). The higher magnification in $D$ displays the loose terminal meshwork (arrowheads) at the level of the former Purkinje cell layer and an atrophic arbor (arrows) radiating in the molecular layer. $M L$, molecular layer; $G L$, granular layer. Scale bars: $30 \mu \mathrm{m}$ in $A$ and $B ; 50 \mu \mathrm{m}$ in $C ; 20 \mu \mathrm{m}$ in $D$.

ported previously, a detailed description of these different stages of Purkinje cell degeneration will be given hereafter.

The earliest and most diffused degenerative abnormalities affected Purkinje cell axons. The first noticeable changes (Fig. $5 A, B)$ were a moderate thickening of this neurite and the appearance of prominent recurrent collaterals, which ended in well-developed terminal arbors along the granular-molecular layer interface or into the molecular layer (Fig. 5B). The corticofugal axons were usually detectable at this stage, but in some instances only the arciform fiber could be disclosed. At a more advanced stage of degeneration (Fig. $5 C$ ), the axons and recurrent collaterals were strongly thickened and bore several torpedoes of various sizes. Arciform recurrent fibers now ended with rather atrophic terminal plexuses, made of a few thick branches 
with large retraction clubs. Such features were common for the few surviving Purkinje neurons seen in the oldest mutants. At the very final stages of degeneration (Fig. 5D), recurrent branches were no longer present and the whole axon was reduced to an extremely thick process with several large torpedoes, which usually ended in the deep granular layer in an oversized retraction club.

Also, the dendrites of $t b l$ Purkinje cells displayed important regressive changes, which appeared to be slightly delayed with respect to axon abnormalities. The first detectable degenerative modifications (Fig. $5 E, G$ ) involved a mild thickening of proximal dendrites associated with the appearance of large swellings at branching points. In addition, in many instances the proximal dendritic ramifications were studded with huge amounts of spines (Fig. 5E,G). As dendritic abnornalities progressed, swellings became more and more numerous and diffused. In some instances (Fig. $5 F$ ), such changes were restricted to a portion of the dendritic tree and, occasionally (Fig. $5 G$ ), one of the proximal branches abruptly ended in a large bulb, from which several thin straight processes emanated. In general, however, the regressive modifications uniformly affected the whole arbor and evolved towards the complete degeneration following different morphological stages (Fig. 6A-E). The progressive increase in the number of swellings resulted in a beaded appearance of the dendritic tree (Fig. 6A) and was followed by the fragmentation of the dendrites, which first affected the distal compartments (Fig. 6B). In many instances, this process ended in the complete disintegration of the whole neuron (Fig. $6 \mathrm{C}$ ). Less frequently, however, there was a gradual withdrawal of the dendritic branches (Fig. 6D) which only spared a few proximal ramifications (Fig. 6E). It is not clear whether cell death occurred at this time or the process evolved up to the complete resorption of the dendritic tree.

Climbing fibers. The climbing fibers that contacted surviving Purkinje cells in adult $t b l$ mice were affected by variable structural abnormalities. Indeed, some of the arbors showed an almost normal morphology and distribution along the proximal dendritic compartment (Fig. 7A). Nevertheless, most fibers were characterized by extensive varicose plexuses, which enveloped the Purkinje somata and primary dendrites, whereas only a few atrophic branches with sparse boutons impinged upon secondary and tertiary dendritic branches (Fig. $7 B, C$ ). Finally, the whole arbor became atrophic, but also in these instances a few varicose branches in the unusual perisomatic location could be disclosed (Fig. 7D).

The terminal distribution of target-deprived arbors (Fig. 7E,F) was somewhat similar to that seen in $p c d$ mice. In fact, also in $t b l$ cerebella it was possible to disclose two distinct levels of termination. (1) Fine terminal meshworks, that were strictly confined in a thin layer of cortex at the granular-molecular layer interface. Such fibers were often mixed to the terminal ramifications of Purkinje collaterals and fine terminal processes from mossy fibers, which also preferentially ended at this location (Fig. 7G). (2) Atrophic monoplanar arbors in the molecular layer, whose structural features were similar to those described for $n r$ and $p c d$ mutants (Fig. $7 E, F$ ), although most of them reached the upper region of this layer.

In conclusion, the comparison of the examined mutations revealed a graded extension of target-deprived climbing fiber arbors in the molecular layer. Such arbors were almost absent in $L c$; they were confined to the deep regions of the layer in the $n r$, and they radiated through its whole extent in pcd and $t b l$ mice.

\section{Climbing fibers and Purkinje cells following mechanical lesions of the cerebellar cortex}

Mechanical lesions of the cerebellar cortex were obtained by passing a microscalpel through the cerebellar parenchyma. This technique leads to the section of the axons that run in the folial white matter. Purkinje cells survive the axotomy (Dusart and Sotelo, 1994). Nevertheless, in the vicinity of the lesion site many Purkinje cells degenerate, either directly attained by the mechanical injury or deprived of their vascular supply, but the normal cortical lamination is maintained (Brand and Mugnaini, 1976; Dusart and Sotelo, 1994). Climbing fibers are spared in those of such areas that are located proximally with respect of the lesion, so that it is possible to examine their morphological changes occurring after the fast degeneration of target neurons.

The morphological features of these target-deprived climbing fibers (Fig. 8A) strongly resembled those observed following the fast neurotoxin-induced Purkinje cell degeneration (Armengol et al., 1989; Rossi et al., 1993). The axonal arbors, which displayed the typical monoplanar orientation, were made of a few rather thin and long branches, which exhibited rare varicosities. Enlarged round-shaped boutons were also occasionally present. By contrast, almost no terminal branches were evident at the granular-molecular layer interface.

A few Purkinje cells that survived the mechanical and/or vascular lesion (Fig. 8B) were affected by axonal and dendritic changes, similar to those described for mutant Purkinje cells (Sotelo and Triller, 1979; Sotelo, 1990a,b; this article), following axotomy (Ramón y Cajal, 1928; Dusart and Sotelo, 1994) or in the case of Purkinje cells surviving after injection of kainic acid (Rossi et al., 1994b). In some instances, the climbing fibers contacting such cells were also labeled. Interestingly, some of these axons displayed extensive terminal plexuses around the soma and the primary dendrite, whereas more distal branches were characterized by variable degrees of atrophy (Fig. $8 C, D$ ).

\section{Discussion}

This article was aimed at investigating the fate of adult climbing fibers following target deprivation by comparing their morphological changes in two different conditions: (1) in mutant mouse strains, where Purkinje cells slowly degenerate within several weeks, and (2) after mechanical lesions of the cerebellar cortex, where a fast Purkinje cell death is induced. Both experimental conditions have substantially confirmed the previous results obtained from neurotoxically lesioned rat cerebella (Armengol et al., 1989; Rossi et al., 1993); that is, target-deprived climbing fibers become atrophic, but remain for long times in their terminal areas. Nevertheless, the morphology and termination pattern of climbing fibers in the two conditions were remarkably different. In addition, the observation of climbing fibers contacting degenerating Purkinje cells in mutant mice revealed that important structural abnormalities affect the terminal arbor well before the complete disappearance of its target neuron. Although these dissimilarities between mutant and lesioned mice might suggest that unrelated regressive phenomena occur in the different conditions, we propose here that they can all be referred to common mechanisms, which primarily concern an altered or disrupted interaction between the axon and its target. 
Are the structural modifications of climbing fibers only related to target loss?

In the present experiments, Purkinje cell degeneration was either an intrinsic effect of the mutation or artificially induced by the mechanical injury. In both approaches, no exogenous substances were introduced in the cerebellum, which could directly affect the morphology of climbing fibers, such as in the case of neurotoxic lesions (Armengol et al., 1989; Rossi et al., 1993, 1994b). Nevertheless, the possibility that the observed axonal changes might not be exclusively due to target loss should not be disregarded. Indeed, a remarkable glial reaction occurs following mechanical cerebellar lesions similar to those produced here (Dusart and Sotelo, 1994). In addition, a prominent astrocytic reaction is known to occur in the cerebella of $p c d$ mice (Ghetti et al., 1990), and most likely affects in a similar way the other mutant strains considered in the present study. Such environmental modifications might conceivably induce some structural alterations in the axons projecting to the affected areas. However, a series of considerations argue against this possibility. (1) Previous neurotoxic lesion experiments, where the action of different substances was compared (Rossi et al., 1993), have shown that almost identical changes affect target-deprived climbing fibers in spite of variably intense astroglial reactions. (2) In our mutant mice, many of the climbing fibers which still contacted their Purkinje cell were characterized by extensive perisomatic terminal plexuses and atrophic peridendritic branches. Such features can be hardly attributed to some unspecific environmental change, which would have uniformly affected the whole arbor. (3) In $t b l$ mice, almost normal climbing fibers were seen in the vicinity of strongly atrophic arbors and, most importantly, olivary arbor abnormalities were more related to the pathological changes affecting their own Purkinje cell than to the overall degencrative processes occurring in the neighboring cerebellar cortex. (4) Finally, grafting experiments in pcd mutants (Sotelo and Alvarado-Mallart, 1987) have shown that the atrophic changes of target-deprived arbors can be reversed by the arrival of new target neurons and, hence, that the molecular layer of these mutants can be permissive for the outgrowth of these axons.

If environmental changes are not responsible for the observed climbing fiber modifications, the morphological abnormalities that affect these arbors in the different strains might be envisaged as a direct effect of the mutation on olivary neurons. Indeed, this fact cannot be completely ruled out, and it is possible that some of the distinctive features of the climbing fibers in the different mutant mice are influenced by the genetic background. Nevertheless, evidence obtained with chimeric mice indicate that the inferior olive is not primarily affected by the mutation, at lcast for $L c$ (Wetts and Herrup, 1982) and pcd (Mullen, 1977). In addition, the olivary axons of these mutants are capable of outgrowth and formation of well-developed climbing fibers following grafts of wild-type embryonic Purkinje cells ( $L c$, Dusmenil-Bousez and Sotelo, 1993; pcd, Sotelo and Alvarado-Mallart, 1987; $n r$, Sotelo and Alvarado-Mallart, unpublished observations).

Altogether these considerations strongly support the view that the majority of climbing fiber modifications reported here are directly related to target degeneration.

\section{Times and modes of Purkinje cell degeneration in different mutant strains}

The examination of surviving Purkinje cells in the different mutant mice revealed that each mutation was characterized by a set of distinctive morphological abnormalities affecting Purkinje cells. Indeed, as also reflected by the variable onset time and progression rate of neuronal death, it is clear that the genetic defects responsible for Purkinje cell degeneration in the various strains act through different mechanisms that operate at different life stages. In this respect, although the affected genes in the mutants have still to be identified, they are known to be localized on different chromosomes (Green, 1989). Nevertheless, beyond the dissimilar outcome of each mutation, a set of recurring features could be disclosed. Hence, in almost all the cases, Purkinje cclls displaycd a sequence of axonal changes that started with the hypertrophy of recurrent collateral branches and terminal plexuses and most frequently evolved towards a progressive atrophy and retraction of the neuritic processes. In addition, the dendrites were often thickened or swollen and frequently displayed the "hyperspiny transformation" (Sotelo et al., 1975). Similar Purkinje cell modifications have also been observed in other mutants (Sotelo, 1990a,b), following axotomy (Ramón y Cajal, 1928; Dusart and Sotelo, 1994), after exposure to a sublethal dose of kainic acid (Rossi et al., 1994b) and in several neurodegenerative disorders (Ramón y Cajal, 1928; Netski, 1968; Duchen, 1984). Altogether, these data suggest that a sequence of stereotyped phenomena, which are partly compensatory and partly degenerative (see Ramón y Cajal, 1928), are set up by the Purkinje cell any time it is injured or exposed to an harmful situation, such as a toxic agent, a metabolic defect, or an injury. Among these phenomena, one of major interest for this study concerns the impairment of the normal retrograde interaction between the Purkinje cell and its climbing fiber, which is responsible for the morphological changes affecting the arbor during the degeneration of its target nerve cell.

\section{Regressive modifications of climbing fibers in mutant mice during and after Purkinje cell degeneration}

The analysis of climbing fibers in mutant mice provided two major conclusions: (1) most olivary terminal arbors were already abnormal before the complete degeneration of their Purkinje

Figure 5. $A-G, \Lambda$ xonal and dendritic abnormalities of $t b l$ Purkinje cells. In $A$, a Purkinje cell at an initial stage of its degeneration is shown. The large arrow points to the mildly thickened axon, bearing several recurrent collaterals (small arrows), which end in extensive plexuses (arrowheads) at the granular-molecular layer interface. A similar plexus (arrowheads), which is also extended into the molecular layer, is shown in $B$. The Purkinje cells in $C$ show short and thickened arciform axons (arrows) characterized by large torpedoes (large arrowheads) and atrophic terminal plexuses bearing several enlarged boutons (small arrowheads). At a more advanced stage of degeneration, in $D$, the axon appears as a thick process with several torpedoes (arrowheads), which ends a few tens of $\mu \mathrm{m}$ form its origin in a large retraction club (arrow). The picture in $E$ shows the morphology of Purkinje cell dendrites at an initial stage of degeneration. Arrowheads point to dilatations at branching points. Note the hyperspiny appearance of proximal dendrites. The Purkinje cell shown in $F$ is characterized by severe regressive modifications that affect only a portion of its dendritic tree (arrowheads), whereas other ramifications have retained a more normal structure. In $G$, the arrow points to a proximal Purkinje cell dendrite that abruptly ends with a swollen club from which several thin processes emanate. Arrowheads highlight the hyperspiny proximal dendrites of the Purkinje cell on the right side of the micrograph. $M L$, molecular layer; $G L$, granular layer. Scale bars: $40 \mu \mathrm{m}$ in $A-F ; 30 \mu \mathrm{m}$ in $G$. 

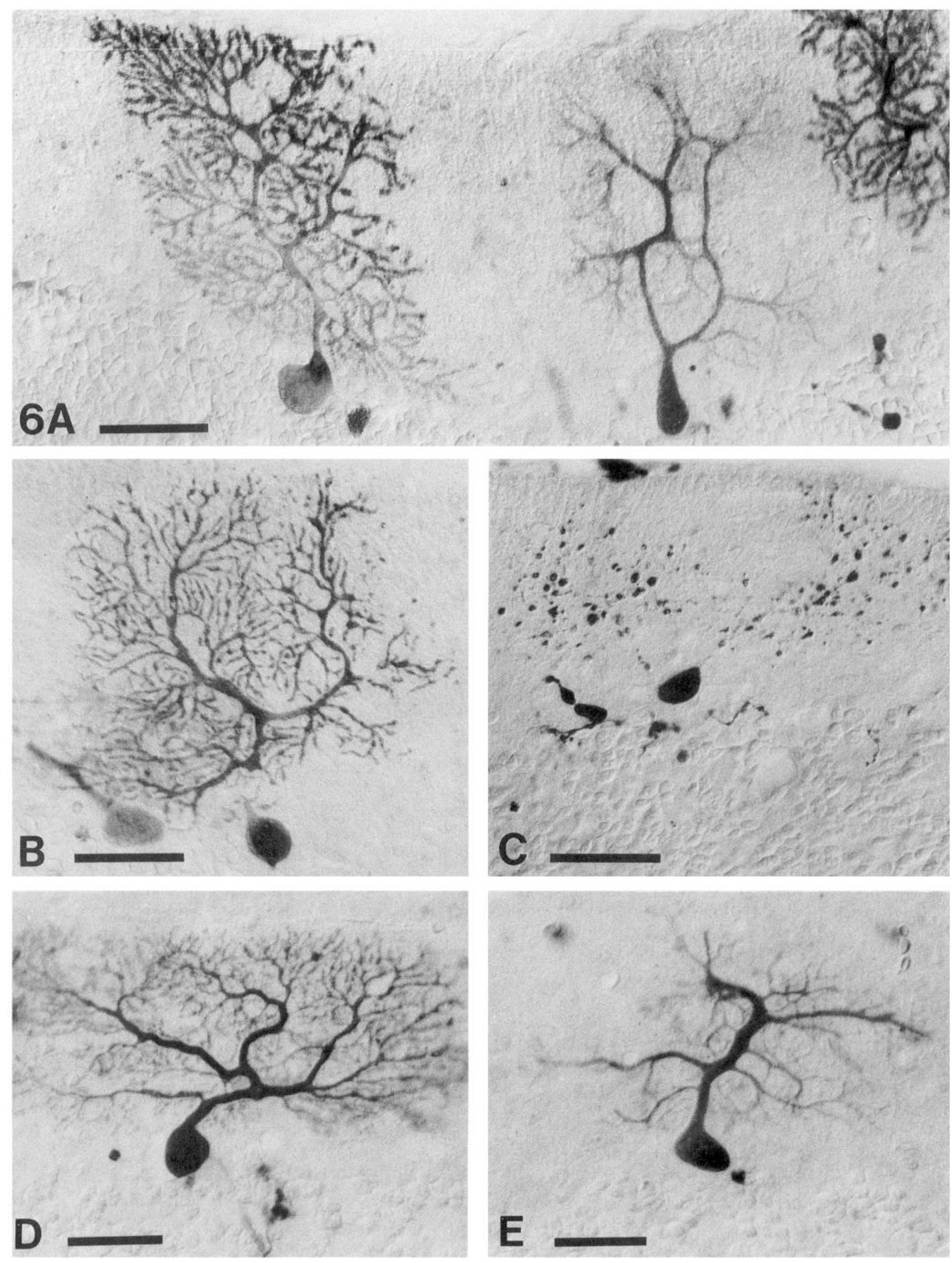

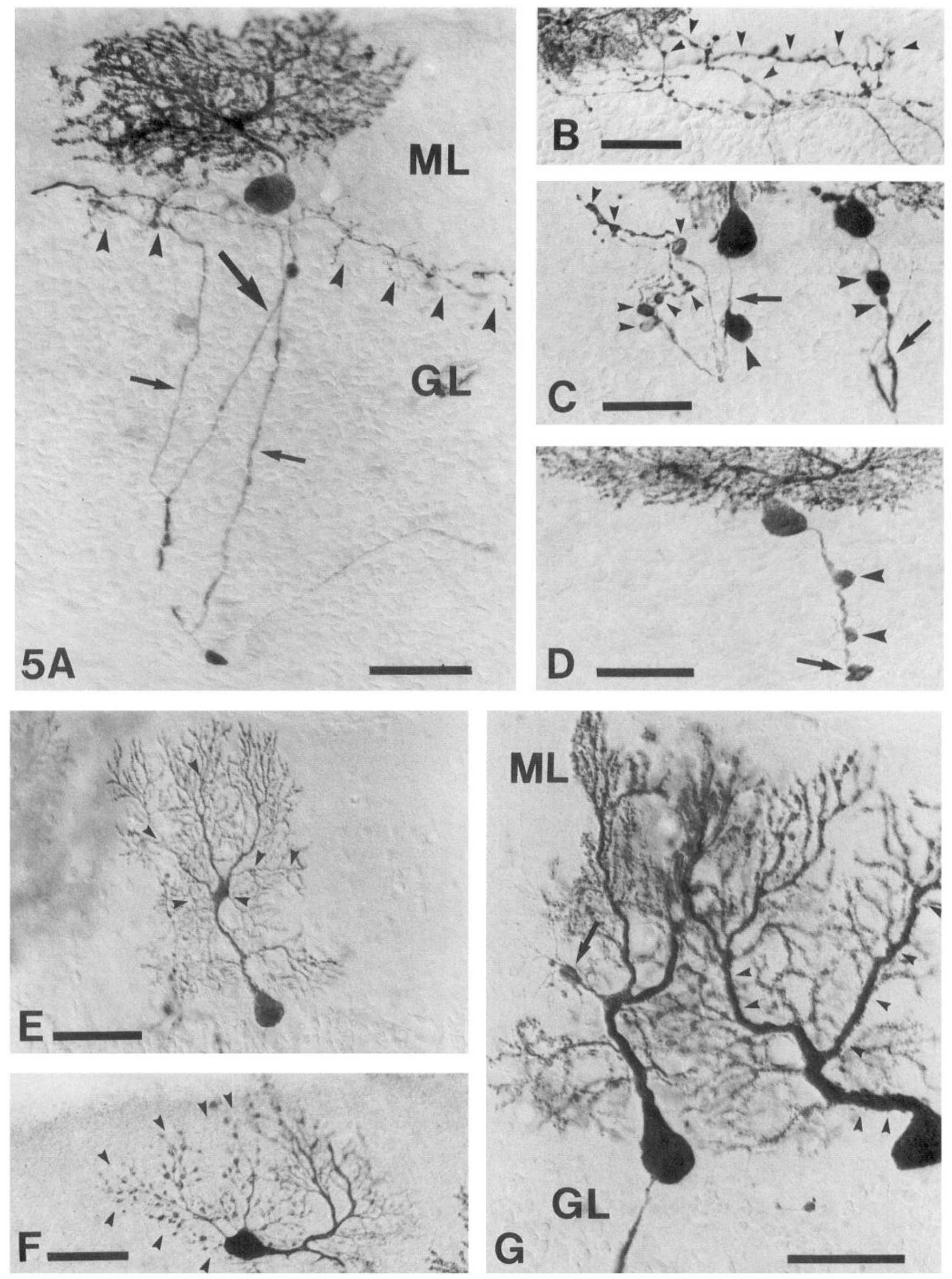
cell, being characterized by perisomatic plexuses and atrophic peridendritic branches; (2) target-deprived arbors displayed peculiar structural features that differ from their counterparts in lesioned cerebella (Armengol et al., 1989; Rossi et al., 1993; this article) for the presence of terminal branches at the granular-molecular layer interface. Several considerations indicate that a direct relationship links these two features.

The perisomatic localization is characteristic of a precise stage of the normal climbing fiber development (Ramón y Cajal, 1911). In the mouse, such branches are withdrawn at about the end of the second postnatal week and the whole terminal arbor translocates to its final peridendritic position (Larramendi, 1969). The persistence of perisomatic climbing fiber synapses in the adult has been described in the hyperspiny Purkinje cell ( $h p c$, Guénet et al., 1983; Sotelo, 1990a,b), staggerer ( $\mathrm{sg}$, Sotelo, 1990b) and $n r$ mutants (Sotelo and Triller, 1979). In addition, the appearance of newly formed terminal climbing fiber branches around the perikaryon in association with the atrophy of peridendritic ramifications has been observed in the case of Purkinje cells that survived after an injection of kainic acid in the adult rat cerebellar cortex (Rossi et al., 1994b). Our mutant mice have been examined during their adulthood. In such a condition it is necessary to determine whether the presence of perisomatic branches has to be attributed to a developmental defect in the translocation process or to an active redeployment of the adult arbor from a peridendritic to a perisomatic position. A definite answer to this question can only be obtained through a careful analysis of climbing fiber development in each mutant. However, our observations on adult animals, together with the available findings from previous reports, indicate that both phenomena occur in the different strains.

The graph in Figure 9, which has been constructed from data drawn from the literature, displays the onset time and the progression of Purkinje cell degeneration in the different mutant strains in relation to the period of normal climbing fiber translocation. Concerning $L c$ and $n r$ mice, the first pathological changes of Purkinje cells appear before the beginning of the translocation phase ( $L c$, Dusmenil-Buusez and Solelo, 1993; $n r$, Landis, 1973). It is well established that this process is almost completely abolished in $L c$ mice (Heckroth et al., 1990) and the abnormal persistence of perisomatic climbing fiber synapses has been reported for the degenerating Purkinje cells of the $n r$ (Landis, 1973). As a consequence, the perisomatic position of climbing fiber branches in the $L c$, and probably also in the $n r$ Purkinje cells, could be attributed to a developmental defect, which hindered the proper climbing fiber translocation. In line with this view, the terminal branches observed at the granular-molecular layer interface after Purkinje cell death most likely represent the atrophied remnants of such perisomatic plexuses. In the case of $L c$, where translocation is severely impaired, these are the only terminal branches that remain. By contrast, in the $n r$, where this process seems to be more mildly affected, a few atrophic ter- minal ramifications are also present in the deeper portion of the molecular layer.

A different interpretation can be drawn for the perisomatic climbing fibers and for the ensuing position of target-deprived branches in $p c d$ and $t b l$ mice. In the $p c d$, the first sign of Purkinje cell pathology are visible at postnatal day 15 , and it is established that a complete climbing fiber translocation occurs (Landis and Mullen, 1978). Unfortunately, no data are available about the onset of the mutation effects in $t b l$ mice. However, the very late beginning of Purkinje cell death (Wassef et al., 1987) and especially the observation of fully peridendritic climbing fibers in our adult $t b l$ mice indicate that also in these mutants a normal translocation takes place. As a consequence, the presence of perisomatic climbing fibers observed in our adult $t b l$ mice is most likely the result of an active process of redeployment of the terminal arbor around the perikaryon and the primary dendrite, similar to that reported for Purkinje cells that survived after kainic acid application (Rossi et al., 1994b). Thereafter, when the Purkinje cell dies, the atrophic remnant of such plexuses remain at the granular-molecular layer interface, whereas the ramifications in the molecular layer are the shred of the former peridendritic arbor. Unfortunately, we were not able to label any climbing fiber still contacting a surviving Purkinje cell in the adult $p c d$. Nevertheless, the strong resemblance of $p c d$ target-deprived climbing fibers with those from $t b l$ mice suggests that a similar sequence of events also takes place in these mutants.

Comparison between target-deprived climbing fibers in mutant animals and in lesioned cerebella

$\Lambda$ s mentioned above, in the lesioned cerebella, target-deprived climbing fibers were exclusively located in the molecular layer, with no terminal branches at the granular-molecular layer interface. In this respect, their morphology was in all identical to that of target-deprived arbors following neurotoxin-induced Purkinje cell death (Armengol et al., 1989; Rossi et al., 1993). Such a difference between lesioned and mutant cerebella is likely due to the very fast degeneration of Purkinje cells induced by the lesion approaches. Indeed, a complete degeneration of Purkinje cells is observed within $24 \mathrm{hr}$ after a kainic acid injection (Herndon et al., 1980), and a similar time course has been reported for the Purkinje neurons affected by a mechanical lesion of the cerebellar parenchyma (Brand and Mugnaini, 1976; Dusart and Sotelo, 1994). It is clear that such a short period of time is not sufficient for the formation of new terminal plexuses around the Purkinje cell somata. As a consequence, the remaining targetdeprived arbor is exclusively formed by branches in the molecular layer, which represent the atrophic remnants of the former peridendritic climbing fiber. However, it is interesting to mention here that some of the injured Purkinje cells that survived close to the lesion site do displayed perisomatic climbing fibers. It is conceivable that such Purkinje cells, which did not die imme-

$\leftarrow$

Figure 6. A-E, Degeneration patterns of $t b l$ Purkinje cells. The micrograph in $A$ shows two Purkinje cells at an advanced stage of their degeneration. The cell on the left side is characterized by a huge amount of swellings at dendritic branching points so that the whole tree acquires a beaded appearance. By contrast, the cell on the right side shows a severe dendritic atrophy that involves the loss of distal branches. The possible progression of these degenerative changes are shown in $B$ and $C$ and in $D$ and $E$, respectively. The beaded dendritic trees undergo a progressive fragmentation $(B)$ that starts from the distal compartments and proceeds centripetally. At the end of the process $(C)$, only scattered dendritic fragments remain in the molecular layer. The micrograph in $D$ shows a Purkinje cell whose distal spiny branchlets appear to be thinner and rarefied. As this process advances $(E)$, most of the distal dendritic compartment disappears, while proximal branches are more preserved. Scale bars: $40 \mu \mathrm{m}$ in $A-C ; 30 \mu \mathrm{m}$ in $D$ and $E$. 

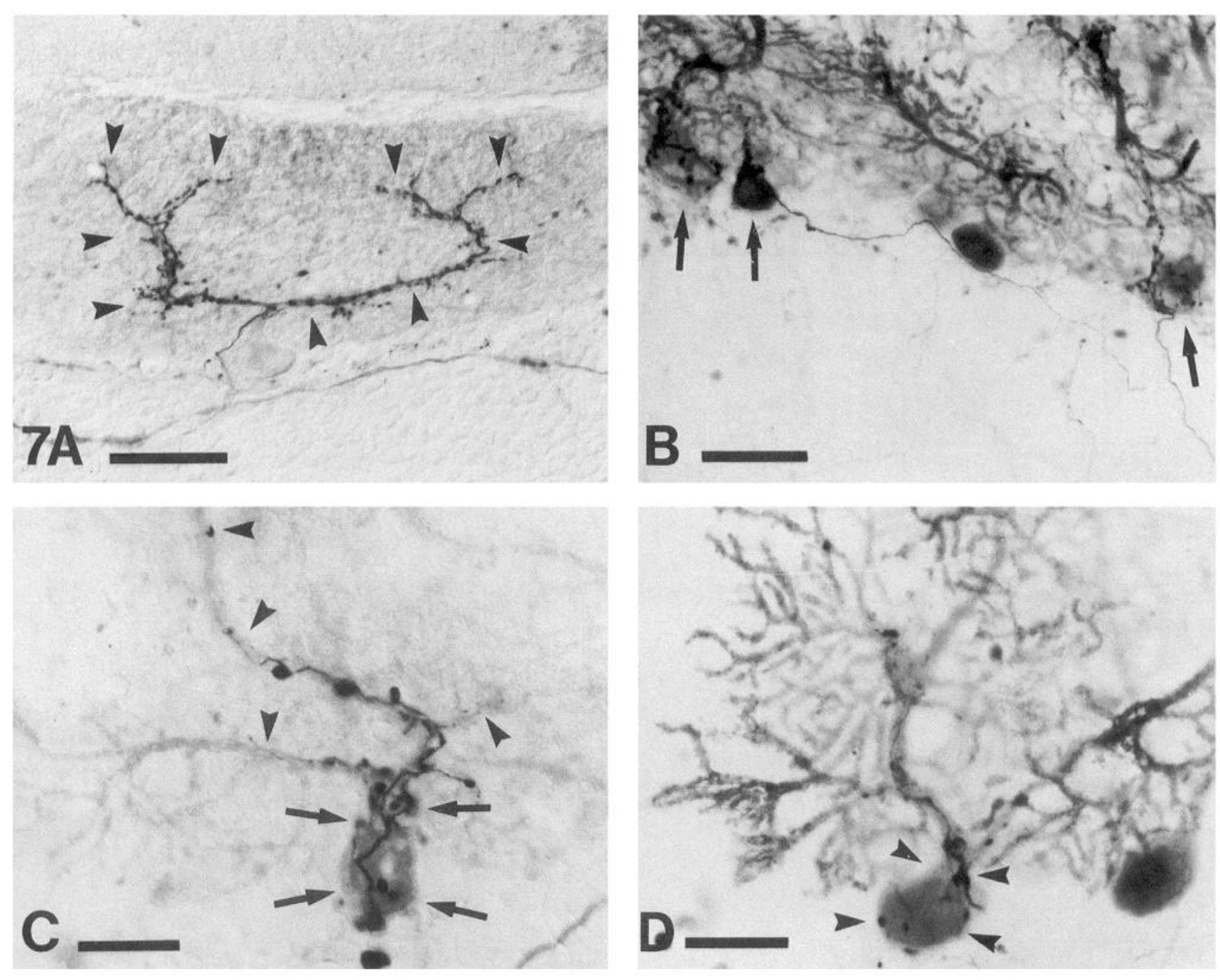

B
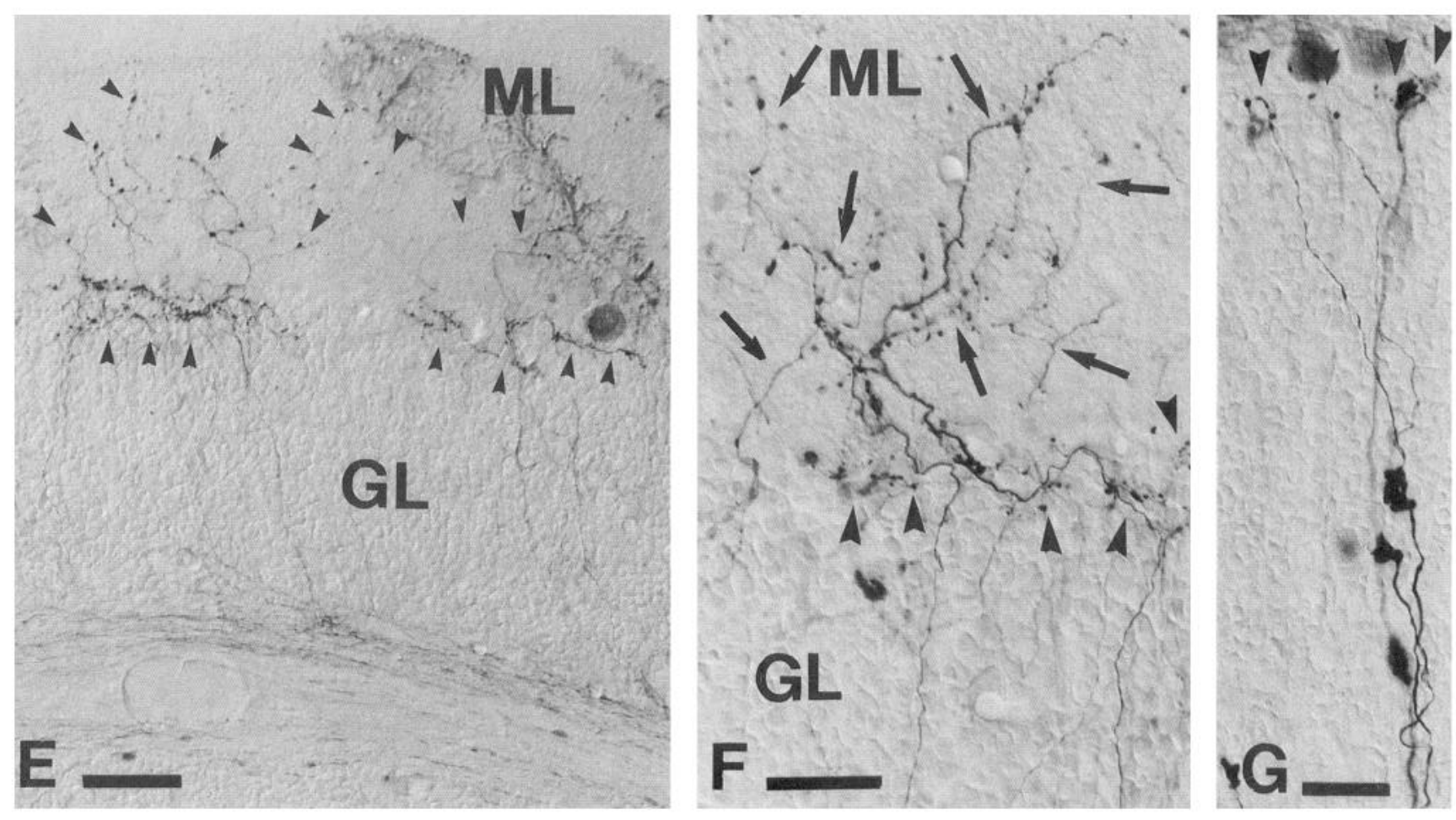

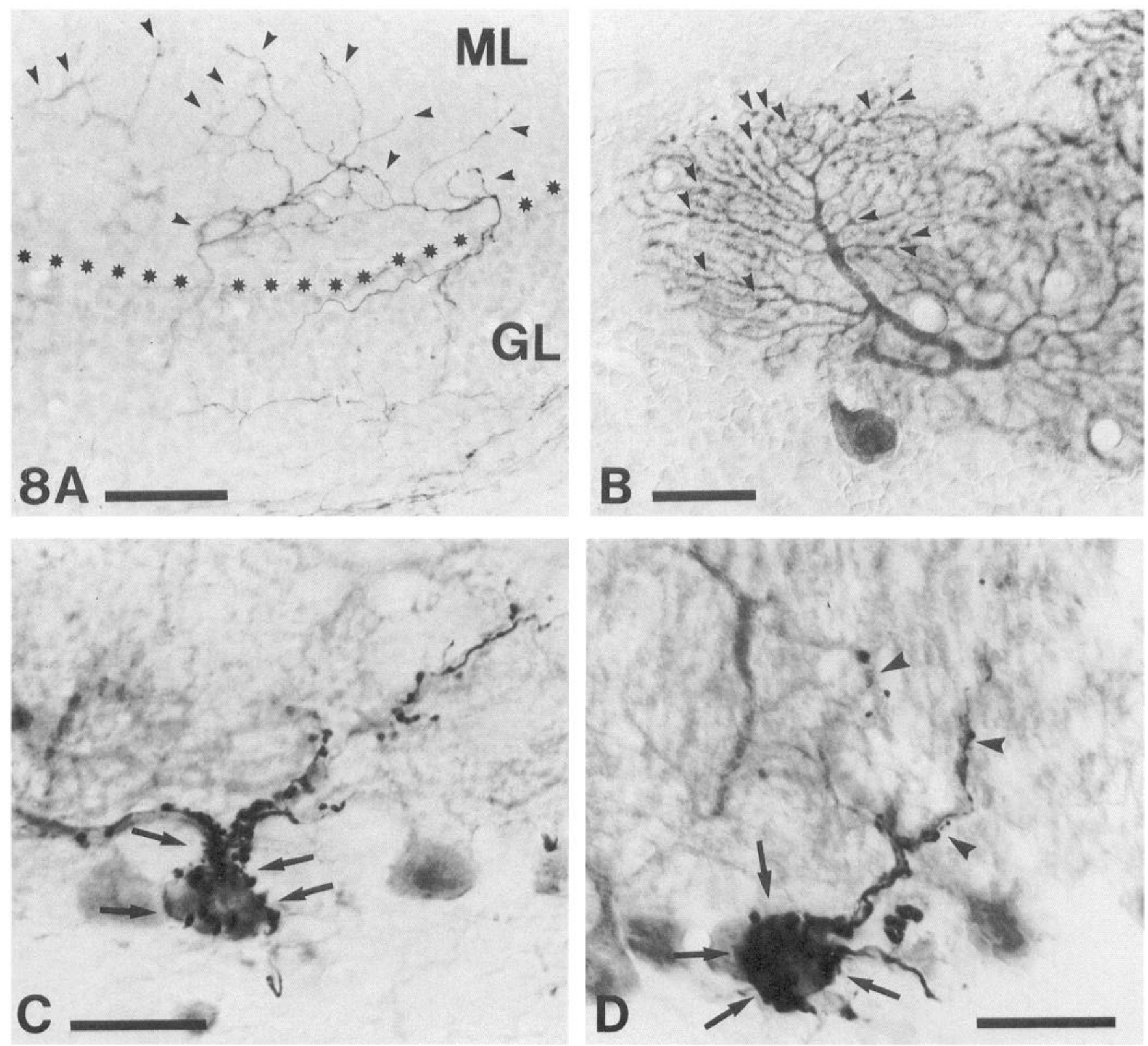

Figure 8. $A-D$, Purkinje cells and climbing fibers following mechanical lesions of the cerebellar cortex. The micrograph in $A$ shows several climbing fibers whose Purkinje cells have been killed by the lesion. Note the atrophic arbors (arrowheads) that span the molecular layer, whereas almost no terminal branches can be seen at granular-molecular layer interface (pointed by asterisks). A Purkinje cell that survived close to the lesion site is shown in $B$. Note the thickened proximal dendrites and the dilatations at branching points (arrowheads). The pictures in $C$ and $D$ show two climbing fibers contacting Purkinje cells that survived in the vicinity of the lesion site. Arrows point to the thick perisomatic climbing fiber plexuses. Note the atrophic peridendritic climbing fiber branches (arrowheads) in $D . M L$, molecular layer; $G L$, granular layer. Scale bars: 50 $\mu \mathrm{m}$ in $A ; 30 \mu \mathrm{m}$ in $B-D$.

Figure 7. $A-G$, Climbing fibers in the adult $t b l$ mouse. The picture in $A$ shows a climbing fiber (arrowheads) that retained an almost normal peridendritic distribution. By contrast, the climbing fibers in $B$ (arrows) are characterized by numerous fine varicose branches that envelope the somata of Purkinje cells. The higher magnification micrograph in $C$ displays a rather thick perisomatic climbing fiber plexus that also covers the initial portion of the dendritic tree (arrows). Note the rare and very thin branches present around the proximal Purkinje cell dendrites (arrowheads). Another severely atrophic climbing fiber is shown in $D$, which bears a number of fine perisomatic branches (arrowheads). The picture in $E$ illustrates the termination pattern of $t b l$ target-deprived climbing fibers (pointed by arrowheads). At a higher magnification $(F)$, the fine terminal plexus at the level of the former Purkinje cell layer (arrowheads) and the atrophic arbors spanning the molecular layer (arrows) can be best appreciated. The picture in $G$ shows the fine terminal mossy fiber branches (arrowheads), which also preferentially end at the granular-molecular layer interface. $M L$, molecular layer; $G L$, granular layer. Scale bars: $40 \mu \mathrm{m}$ in $A$ and $B, 20 \mu \mathrm{m}$ in $C$ and $D ; 50 \mu \mathrm{m}$ in $E ; 30 \mu \mathrm{m}$ in $F$ and $G$. 


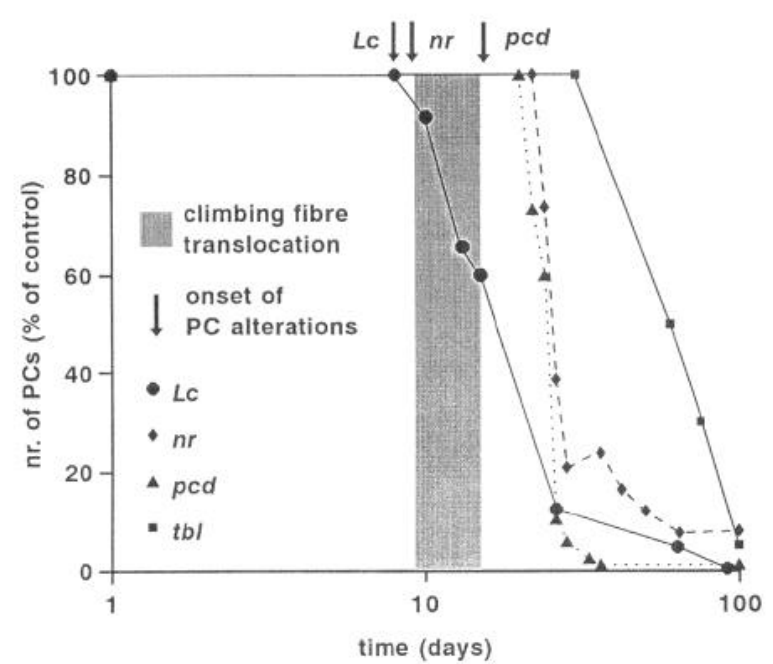

Figure 9. Onset time and progression rate of Purkinje cell degeneration in the different mutant mouse strains. The graph shows the time course of Purkinje cell death in the different mutations in relation to the normal translocation of climbing fibers. In $L c$ and $n r$ mice the Purkinje cell modifications start before the period where translocation takes place, whereas in $p c d$ the degenerative processes initiate after the end of this period (see Discussion). Data about translocation are from Larramendi (1969); Lc from Caddy and Biscoe (1979) and Dusmenil-Bousez and Sotelo (1992); $n r$ from Landis (1973); pcd from Mullen et al. (1976) and Landis and Mullen (1978). Data about $t b l$ have been extrapolated from Wassef et al. (1987). diately after the lesion, underwent the same sequence of stereotyped modifications that affect degenerating mutant Purkinje cells or those exposed to kainic acid. In the case of the present mechanical injuries as well as for the Purkinje cells survived to the excitotoxin injections, perisomatic climbing fiber branches were already present 2 weeks after the lesion. This indicates that the bulk of axonal remodeling phenomena, which involve the withdrawal of most peridendritic ramifications and the formation of extensive terminal plexuses, rapidly develops within a rather short period of time after the injury.

\section{Concluding remarks: target control on the structure of the climbing fiber arbor}

The present observations, together with other ones from previous work (Armengol et al., 1989; Rossi et al., 1993, 1994b), have shown that several factors contribute to determine the structural features of target-deprived climbing fibers. Among these factors of major importance are (1) the time of onset and (2) the progression rate of Purkinje cell degeneration. The results of these studies on target degeneration indicate that continuous dynamic interactions between the Purkinje cell and its climbing fiber control the outgrowth, the maintenance, and the plasticity of the olivary arbor. It has been proposed that specific cues, which are most likely located on the surface of the Purkinje cell, direct the outgrowth and the maintenance of the olivary arbor (Rossi et al., 1993, 1994a). As shown in Figure 10, during normal development the progressive displacement of such cues

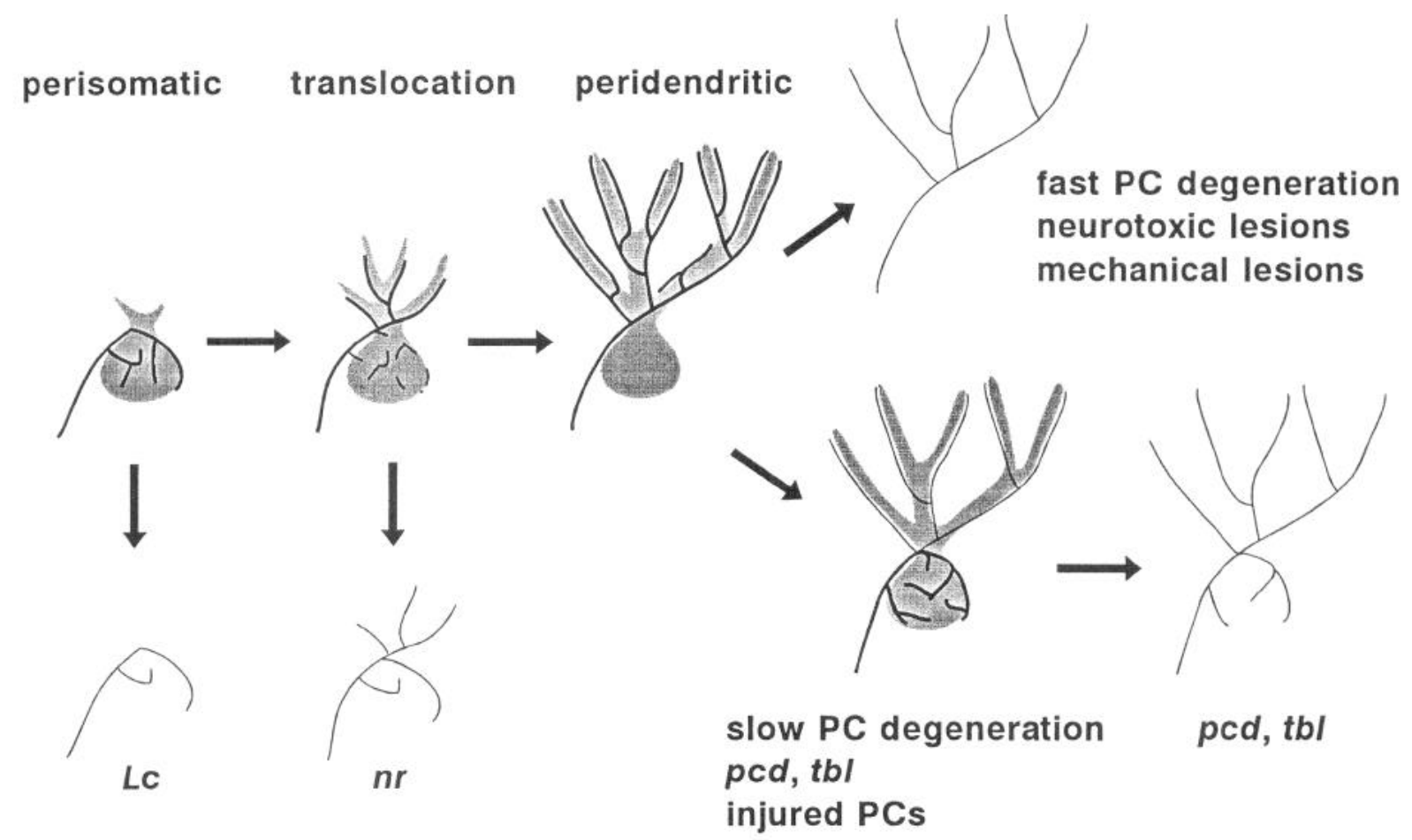

Figure 10. Regressive modifications of climbing fibers in relation to the onset time and progression rate of Purkinje cell degeneration. The normal climbing fiber development is characterized by a stage where the terminal arbor surrounds the Purkinje cell perikaryon. Thereafter, after the maturation of Purkinje cell dendrites, the perisomatic branches are withdrawn and the arbor translocates into the adult peridendritic position. In mutants where this process is abolished $(L c)$ or affected $(n r)$ the remaining target-deprived branches are mainly located at the level of the former Purkinje cell layer. By contrast, when Purkinje cells die after the completion of the translocation process, two different outcomes are possible. In the case of slowly degenerating Purkinje cells, the peridendritic branches become atrophic and new perisomatic plexuses appear. If such degenerative processes progress up to the death of the Purkinje cell (such as in $p c d$ and $t b l$ mice), the perisomatic branches also become atrophic. As a consequence, these target-deprived climbing fibers retain a few terminal branches at the level of the former Purkinje cell layer and an atrophic arbor in the molecular layer. By contrast, when a fast Purkinje cell death occurs (such as in the case of toxic or mechanical lesions), no perisomatic branches are formed and the target-deprived arbor is exclusively made of branches radiating in the molecular layer. 
from the somatic to the dendritic surface determines the natural translocation of the climbing fiber (Ramón y Cajal, 1911). Such a process is defective in $L c$ and, probably, in $n r$ mice. In the intact adult, the role of these factors would be that of maintaining the normal structure of the terminal arbor. In any instance, when the target cell is rapidly removed, such as in the loxic or mechanical lesions, the sudden loss of this support determines the progressive withdrawal of the distal climbing fiber branches and the atrophy of the whole arbor (Armengol et al., 1989; Rossi et al., 1993; this article). In addition, in many situations where the adult Purkinje cell is injured or affected by some pathological condition, such cues are withdrawn from the proximal dendritic compartment and are redeployed at the perisomatic level (Rossi et al., 1994b; this article). As a consequence, the peridendritic climbing fiber ramifications become atrophic and new terminal branches are developed around the perikaryon while Purkinje dendrites undergo the "hyperspiny transformation" (Sotelo et al., 1975; Rossi et al., 1994b). In some instances, such as in the case of Purkinje cells survived after kainic acid application (Rossi et al., 1994b), such an abnormal relationship seems to become permanent. However, in the case of $t b l$ and $p c d$ mice, the ensuing degeneration of the Purkinje cells deprives the perisomatic branches of their target support and determines their atrophy. In other words, the phenotype of target-deprived climbing fibers always reflects the preceding natural history of their interaction with the Purkinje cells.

The fine mechanisms that regulate the distribution of these cues on different compartments of the Purkinje cell remain to be elucidated. However, it is worth speculating that the gross changes in their distribution pattern occurring in severely affected Purkinje cells may represent an exaggerated expression of the cellular processes that underlay the physiological plasticity and synaptic turnover of the climbing fiber.

\section{References}

Armengol JA, Sotelo C, Angaut P, Alvarado-Mallart RM (1989) Organization of host afferents to cerebellar grafts implanted into kainate lesioned cerebellum of adult rats. Hodological evidence for the specificity of graft-host interactions. Eur J Neurosci 1:75-93.

Brand S, Mugnaini E (1976) Fulminant Purkinje cell death following axotomy and its use for analysis of dendritic arborization. Exp Brain Res 26:105-119.

Caddy KWT, Biscoe TJ (1979) Structural and quantitative studies on the normal and lurcher mutant mouse. Philos Trans R Soc Iond [Biol] 287:167-201.

Curtis DR, Malik R (1985) A neurophysiological analysis of the effect of kainic acid on nerve fibers and terminals in the cat spinal cord. $J$ Physiol (Lond) 368:99-108.

De La Cruz RR, Pastor AM, Delgado-Garcia JM (1994) Effects of target depletion on mammalian central neurons: morphological correlates. Neuroscience 58:59-79.

Duchen LW (1984) General pathology of neurons and neuroglia. In: Greenfield's neuropathology, 4th ed (Hume AJ, Corsellis JAN, Duchen LW, eds), pp 1-52. London: Arnold.

Dusart I, Sotelo C (1994) Lack of Purkinje cell loss in adult rat cerebellum following protracted axotomy: degenerative changes and regenerative attempts of the severed axons. J Comp Neurol 347:211232.

Dumesnil-Bousez N, Sotelo C (1992) Early development of the Lurcher cerebellum: Purkinje cell alterations and impaired synaptogenesis J Ncurocytol 21:506-529.

Dumesnil-Bousez N, Sotelo C (1993) Partial reconstruction of the adult Lurcher cerebellar circuitry by neural grafting. Neuroscience 55:121.

Ghetti B, Triarhou LC, Alyea CJ, Low WC, Chang AC (1990) Timing of neuronal replacement in cerebellar degenerative ataxia of Purkinje cell type. Prog Brain Res 82:442-455.

Glanzman DL, Kandel ER, Schacher S (1990) Target-dependent struc- tural changes accompanying long-term synaptic facilitation in Aplysia neurons. Science 249:799-802.

Green MC (1989) Catalog of mutant genes and polymorphic loci. In: Genetic variants and strains of the laboratory mouse, 2d ed (Lyon MF, Searle AG, eds), pp 12-403. London: Oxford UP.

Guénet JL, Sotelo C, Mariani J (1983) Hyperspiny Purkinje cell, a new neurological mutation in the mouse. J Hered 74:105-108.

Heckroth JA, Eisenman LM (1988) The olivocerebellar projection in "lurcher" mutant mice. Neurosci Lett 85:199-204.

Heckroth JA, Goldowitz D, Eisenman LM (1990) Olivocerebellar fibre maturation in normal and mutant mice: defective development in Lurcher. J Comp Neurol 291:415-430.

Herndon RM, Coyle JT, Addicks E (1980) Ultrastructural analysis of kainic acid lesion to the cerebellar cortex. Neuroscience 5:10151026.

Isacson O, Brundin P, Gage FH, Björklund A (1985) Neural grafting in a rat model of Huntington's disease: progressive neurochemical changes after neostriatal ibotenate lesions and striatal tissue grafting. Neuroscience 16:799-817.

Ito $M$ (1984) The cerebellum and neural control. New York: Raven.

Landis SC (1973) Ultrastructural changes in the mitochondria of cerebellar Purkinje cells of nervous mutant mice. J Cell Biol 57:782797.

Landis SC, Mullen RJ (1978) The development and degeneration of Purkinje cells in pcd mutant mice. J Comp Neurol 177:125-144.

Larramendi LMH (1969) Analysis of synaptogenesis in the cerebellum of the mouse. In: Neurobiology of cerebellar evolution and development (Llinás R, ed), pp 803-843. Chicago: American Medical Association.

Mullen RJ (1977) Site of $p c d$ gene action and Purkinje mosaicism in cerebella of chimeric mice. Nature 270:245-247.

Mullen RJ, Eicher EI, Sidman RL (1976) Purkinje cell degeneration, a new neurological mutation in the mouse. Proc Natl Acad Sci USA 73:208-212.

Netski MG (1968) Degenerations of the cerebellum and its pathways. In: Pathology of the nervous system, Vol I (Minckler J, ed), pp 1163 1185. New York: McGraw-Hill.

Nothias F, Wictorin K, Isacson O, Björklund A, Peschanski M (1988) Morphological alteration of thalamic afferents in the excitotoxically lesioned striatum. Brain Res 461:349-354.

Oppenheim RW (1991) Cell death during development of the nervous system. Annu Rev Neurosci 14:453-501.

Pearson HE, Stoffler DJ, Sonstein WJ (1992) Response of retinal terminals to loss of postsynaptic target neurons in the dorsal lateral geniculate nucleus of the adult cat. J Comp Neurol 315:333-343.

Peschanski M, Besson JM (1987) Structural alteration and possible growth of afferents to kainate lesion in the adult thalamus. J Comp Neurol 258:185-203.

Peterson GM, Moore RY (1980) Selective effects of kainic acid on diencephalic neurons. Brain Res 202:165-182.

Purves D, Snider WD, Voyvodic JT (1988) Trophic regulation of nerve cell morphology and innervation in the autonomic nervous system. Nature 336:123-128.

Ramón y Cajal S (1911) Histologie du système nerveux de l'homme et des vertébrés. Paris: Maloine.

Ramón y Cajal S (1928) Degeneration and regeneration of the nervous system. Reprint (De Felipe J, Jones EG, eds; May RM, trans). London: Oxford UP, 1991.

Rossi F, Borsello T, Vaudano E, Strata P (1993) Regressive modifications of target-deprived climbing fibres following Purkinje cell degeneration in the cerebellar cortex of the adult rat. Neuroscience 53 : 759-778.

Rossi F, Borsello T, Strata P (1994a) Embryonic Purkinje cells grafted on the surface of the adult uninjured rat cerebellum migrate in the host parenchyma and induce sprouting of intact climbing fibres. Eur J Neurosci 6:121-136.

Rossi F, Borsello T, Strata P (1994b) Exposure to kainic acid mimics the effects of axotomy in cerebellar Purkinje cells of the adult rat. Eur J Neurosci 6:392-402.

Schacher S, Montarolo PG (1991) Target-dependent structural changes in sensory neuron of Aplysia accompany long-term heterosynaptic inhibition. Neuron 6:679-690.

Sidman RL, Green MC (1970) "Nervous", a new mutant mouse with cerebellar disease. In: Les mutants pathologiques chez l'animal (Sabourdy M, ed), pp 69-79. Paris: Editions du CNRS. 
Sofroniew MV, Galletly NP, Isacson O, Svendsen CN (1990) Survival of adult basal forebrain cholinergic neurons after loss of target neurons. Science 247:338-342.

Sofroniew MV, Cooper JD, Svendsen CN, Crossman P, Ip NY, Lindsay RM, Zafra F, Lindholm D (1993) Atrophy but not death of adult septal cholinergic neurons after ablation of target capacity to produce mRNAs for NGF, BDNF and NT3. J Neurosci 13:5263-5276.

Sotelo C (1990a) Axonal abnormalities in cerebellar Purkinje cells of the "hyperspiny Purkinje cell" mutant mouse. J Neurocytol 19:737755.

Sotelo C (1990b) Cerebellar synaptogenesis: what can we learn from mutant mice. J Exp Biol 153:225-249.

Sotelo C, Alvarado-Mallart RM (1987) Embryonic and adult neurons interact to allow Purkinje cell replacement in mutant cerebellum. Nature 327:421-423.

Sotelo C, Triller A (1979) Fate of presynaptic afferents to Purkinje cells in the adult nervous mutant mouse: a model to study presynaptic stabilization. Brain Res 175:11-36.

Sotelo C, Hillman DE, Zamora AJ, Llinás R (1975) Climbing fibre deafferentation, its action on Purkinje cell dendritic spines. Brain Res 98:574-581.

Spencer R, Charman M, Ematage JS, Lawson DEM (1976) Production and properties of vitamin D-induced mRNA for chick calcium-binding protein. Eur J Biochem 71:399-409.

Steward O (1991) Synapse replacement on cortical neurons following denervation. In: Cerebral cortex, Vol 9 (Jones EG, Peters A, eds), pp 81-132. New York: Plenum.

Steward O (1992) Signals that induce sprouting in the central nervus system: sprouting is delayed in mouse exhibiting delayed axonal degeneration. Exp Neurol 118:340-351.

Walker PD, McAllister JP (1986) Anterograde transport of horseradish peroxidase in the nigrostriatal pathway after neostriatal kainic acid lesions. Exp Neurol 93:334-347.

Wassef M, Sotelo C, Cholley B, Brehier A, Thomasset M (1987) Cerebellar mutations affecting the postnatal survival of Purkinje cells disclose a longitudinal pattern of differentially sensitive cells. Dev Biol 124:379-389.

Wetts R, Herrup K (1982) Interaction of granule, Purkinje and inferior olivary neurons in Lurcher chimeric mice. I. Quantitative studies. J Embryol Exp Morphol 68:87-98.

Wilson DB (1976) Histological defects in the cerebellum of adult lurcher (lc) mice. J Neuropathol Exp Neurol 35:40-45.

Woodward WR, Meshul CK, Coull BM (1989) Ultrastructural and functional evidence for the survival of corticogeniculate neurons in kainic-acid lesioned geniculate nucleus. Brain Res 494:42-54. 